\title{
ZnS nanoparticles decorated graphene nanoplatelets as immobilisation matrix for glucose biosensor
}

\author{
G. Suganthi ${ }^{1}$, T. Arockiadoss ${ }^{2}$, T. S. Uma ${ }^{1 *}$ \\ ${ }^{1}$ Bio products laboratory, Central Leather Research Institute, Adyar, Chennai 600 036, Tamil Nadu, India \\ ${ }^{2}$ Department of physics, Madurai Kamaraj University, Madurai 625021, Tamil Nadu, India \\ Shugankarthick@gmail.com, arockiados@gmail.com, tsuma@clri.res.in
}

\begin{abstract}
A glucose biosensor has been fabricated by using $\mathrm{ZnS}$ nanoparticle-substituted graphene nanosheets. Thermally exfoliated graphene nanosheets act as a suitable support for the deposition of $\mathrm{ZnS}$ nanoparticles. In this work, graphene was functionalized with $\mathrm{ZnS}$ nanoparticles by a simple chemical reduction method. The synthesized G/ZnS nanoparticles have been characterized using X-ray diffractometry (XRD), Transmission electron microscopy (TEM), scanning electron microscopy (SEM), energy dispersive spectroscopy (EDS), FT-IR techniques. Aditionally, the Glucose biosensor has been constructed by drop-casting G/ZnS over a conductive carbon support followed by the deposition of Glucose oxidase (GOx) over a G/ZnS electrode. The performance of the biosensor was investigated by an electrochemical method. The resultant bioelectrode retains its biocatalytic activity and offers fast, highly-sensitive glucose quantification and a shelf-life of about 10 weeks under refrigerated conditions.
\end{abstract}

Keywords: Glucose oxidase, $\mathrm{ZnS}$ nanoparticles, graphene, enzymatic, biosensor.

Received: 5 February 2016

\section{Introduction}

Estimation of glucose level in blood is considered as very important for patients suffering from diabetes, heart diseases, chronic kidney failure and other disorders that require continuous glucose monitoring [1,2]. Hence, in recent years, the demand has grown in the field of medical diagnostics for simple and disposable devices that also demonstrate fast response time, user-friendliness, cost-efficiency, and are suitable for mass production [3,4]. Biosensor technologies offer the potential to fulfill these criteria through an interdisciplinary combination of approaches from nanotechnology, chemistry and medical science. Among the various analytical methods, enzymatic methods offer several advantages in terms of rapid determination, sensitivity and selectivity [5].

The immobilization of enzymes is the most critical step in biosensor fabrication, and thus, confers many operational advantages including high selectivity and possible modulation of the catalytic properties. Carbon-based nanomaterials are popularly used in electrochemical method due to its large surface area, excellent electrical and mechanical properties for enzyme loading and direct electron transfer to obtain low detection limits [6,7]. Glucose oxidase (GOx), a highly specific enzyme, is most widely employed of all enzyme-based glucose biosensors. It catalyzes the oxidation of glucose to gluconolactone and hydrogen peroxide.

Among the various metal nanoparticles, zinc sulfide nanoparticles are an interesting material with a high isoelectric point that allows easy immobilization of an enzyme (with a low Isoelectric point) through electrostatic interaction [8,9]. Furthermore, its high chemical stability and non-toxic nature, as well as its biocompatibility and high electron transfer capability make $\mathrm{ZnS}$ a promising material for building an enzymatic sensor by immobilizing the appropriate biomolecules without electron mediators [10,11].

Graphene, a nanostructure of carbon, is a two-dimensional honeycomb crystalline single layer lattice of carbon $[12,13]$. It has received enormous interest in various areas of research owing to its large specific surface area, extraordinary electrical and thermal conductivities, high mechanical stiffness, good biocompatibility and low manufacturing cost. The biocompatibility, high conductivity, and the large surface area of graphene have made it an ideal candidate in the development of bio-electronic devices. The large surface area and excellent electrical conductivity of graphene allow it to act as an "electron wire" between the redox centers of an enzyme or protein and an electrode's surface. Rapid electron transfer facilitates accurate and selective detection of biomolecules [14, 15].

Currently, a wide variety of electrode devices are available for electrochemical determination. Toray Carbon paper (GDL) has received much attention in several electrochemical applications such as biofuel cells, supercapactiors, batteries and biosensors, owing to its large surface-volume ratio, high porosity and good electrical conductivity [16].

Herein, we present the design and fabrication of Carbon paper (CP) macro-substrate/Graphene(G)/ZnS based electrodes. The results show good performance, fast response times, nice stability and reproducibility, and low 
detection limits for the $\mathrm{ZnS} / \mathrm{G}$ nanocomposite based on the reduction of $\mathrm{H}_{2} \mathrm{O}_{2}$ by immobilized glucose oxidase on the composite.

\section{Materials and Methods}

\subsection{Materials}

Glucose oxidase (GOD, type x-s from Aspergillus niger), D-(+)-glucose, Flake graphite powder (99.99\% SP-1, Bay carbon, average particle size $45 \mathrm{~mm}$ ), were purchased from Sigma Aldrich. Carbon paper (TGPH-60) was obtained from Toray Ind., Hydrogen peroxide $\left(\mathrm{H}_{2} \mathrm{O}_{2}, 30 \% \mathrm{wt} / \mathrm{V}\right)$ was purchased from Fisher scientific. Concentrated sulfuric acid $\left(\mathrm{H}_{2} \mathrm{SO}_{4}, 99 \%\right)$, concentrated nitric acid $\left(\mathrm{HNO}_{3}, 98 \%\right)$, potassium permanganate $\left(\mathrm{KMnO}_{4}\right)$ were obtained from Rankem Chemicals, India and used without further purification. Zinc sulfide nanoparticles were prepared by an aqueous chemical method using zinc chloride $\left(\mathrm{ZnCl}_{2}\right)$ and Sodium Sulfide $\left(\mathrm{Na}_{2} \mathrm{~S}\right)$. 0.1M phosphate buffer solution (PBS, pH 7) prepared using were prepared by mixing stock standard solution of $\mathrm{K}_{2} \mathrm{HPO}_{4}$. The aqueous stock solution of $\mathrm{KH}_{2} \mathrm{PO}_{4}$ was prepared using deionized water (DI water). The common chemicals used for the preparation of buffers, etc., were of analytical reagent grade. All the electrochemical studies and synthesis were performed using deionized (DI) water.

\subsection{Synthesis of Graphene (G)}

Graphene was synthesized according to thermal exfoliation method using GO as the precursor [12]. Thermal exfoliation was done in a quartz tube at $800{ }^{\circ} \mathrm{C}$. For dispersing metal nanoparticles over graphene, the as-prepared graphene $(G)$ was functionalized by continuous stirring in a solution of concentrated sulfuric and nitric acids $(3: 1)$ for $30 \mathrm{~min}$.

\subsection{Synthesis of $\mathrm{ZnS} / \mathrm{G}$ nanocomposite}

Zinc chloride and sodium sulfide was taken such that the ratio between the $\mathrm{ZnS}$ produced and the $\mathrm{f}-\mathrm{G}$ is $3: 7$. In a typical preparation, functionalized graphene and $1 \mathrm{M}$ zinc chloride was prepared in $100 \mathrm{ml}$ of deionized water. Then solution of $1 \mathrm{M}$ sodium sulfide was added dropwise to the magnetically stirred mixture at $70{ }^{\circ} \mathrm{C}$, which resulted in formation of $\mathrm{ZnS} / \mathrm{f}-\mathrm{G}$ nano-colloid. The suspension was filtered and washed several times with DI water and finally the residue was dried in a vacuum oven at $60{ }^{\circ} \mathrm{C}$.

\subsection{Materials characterization techniques}

The crystallinity of the synthesized material was characterized by X-ray diffraction technique using PANalytica X'pert pro X-ray diffractometer with $\mathrm{Cu}-\mathrm{K} \alpha$ as the X-ray source. The surface morphology of the sample was examined by SEM (FEI, Quanta 3D) and TEM (TECNAI G F20,S-TWIN). Electrochemical studies were carried out by $\mathrm{CH}$ Instrument, electrochemical workstation with a three-electrode electrochemical cell comprising a $\mathrm{ZnS} / \mathrm{G}$ modified carbon paper electrode as the working electrode, a Pt wire as the counter electrode and a $\mathrm{Ag} / \mathrm{AgCl}(1 \mathrm{M}$ $\mathrm{KCl}$ solution) as the reference electrode. PBS was used as the supporting electrolyte for all the electrochemical studies at ambient temperature.

\subsection{Fabrication of the Bioelectrodes}

The bioelectrode was fabricated over the Carbon paper electrode (CPE). The electrode was modified by a simple drop casting method. First, $1 \mathrm{mg} / \mathrm{ml}$ graphene $(\mathrm{G})$ solution was prepared by ultrasonication of $1 \mathrm{mg}$ of $\mathrm{G}$ in $1 \mathrm{ml}$ of $0.5 \%$ nafion solution. Nafion gives better dispersion as well as stability to the graphene (G). About $15 \mu 1$ of the solution was dropped over the surface of carbon paper electrode and allowed to dry at room temperature. $10 \mu \mathrm{l}$ of GOD was film cast over the dried G film. Finally, another $5 \mu$ l layer of NA was dropped and allowed to dry and kept at $4{ }^{\circ} \mathrm{C}$ to preserve the enzyme activity. The similar procedure was used for fabricating $\mathrm{ZnS} / \mathrm{G}$ electrode. The fabricated electrodes will be termed as $\mathrm{f}-\mathrm{G} / \mathrm{GOD} / \mathrm{NA} / \mathrm{CPE}$ and Au/f-G/GOD/NA/CPE from here onward.

\section{Results and discussion}

\subsection{XRD and FT-IR studies of the samples}

The XRD pattern of the hybrid composite has been compared with the starting material. Fig. 1 depicts the XRD pattern of (a) ZnS and (b) ZnS-G. Well resolved crystalline peaks appear at $13.15^{\circ}, 21.8^{\circ}, 26.6^{\circ}, 31.6^{\circ}$, $40.5^{\circ}$ and $55^{\circ}$ corresponding to $\mathrm{ZnS}$ nanoparticles [10]. Fig. 1(b) shows the diffraction peaks appear at $29.0^{\circ}$, $33.5^{\circ}, 48.1^{\circ}$ and $57.0^{\circ}$ (JCPDS No. 05-0566) corresponding to ZnS nanostructure along with C (002) peak. This indicates the successful functionalization of graphene with $\mathrm{ZnS}$ nanoparticles. 
The compatibility study was carried out using a Perkin Elmer FTIR spectrophotometer in the region of 4000 to $500 \mathrm{~cm}^{-1}$. Spectra for $\mathrm{ZnS}$, graphene and their admixture were obtained and compared. In the Fig. 2(b) FTIR spectra exhibit strong bands appearing in 643, 947, 1129, 1410, 1629 and $3419 \mathrm{~cm}^{-1}$, corresponding to $\mathrm{ZnS}$ nanoparticles [11]. The peak at $612 \mathrm{~cm}^{-1}$ is assigned to the $\mathrm{ZnS}$ band (i.e., corresponding to sulfides). The $\mathrm{O}-\mathrm{H}$ bending region due to absorbed water appear at $1629 \mathrm{~cm}^{-1}$ and $\mathrm{O}-\mathrm{H}$ stretching at $3419 \mathrm{~cm}^{-1}$. From FT-IR spectroscopy shown in Fig. 2(c), it is clear that several types of functional groups, particularly carbonyl and hydroxyl groups have been generated on acid-oxidized graphene sheet surfaces as expected [13]. Examination on surfaces of acid oxidized graphene was carried out using a Fourier transform infrared (FT-IR) spectrophotometer to ensure formation of desired surface functional groups. The absorption spectra at $3441 \mathrm{~cm}^{-1}$ exhibit OH stretching and $\mathrm{OH}$-bending at $1624 \mathrm{~cm}^{-1}$. Hence, the information provided there indicates uniform distribution of $\mathrm{ZnS}$ nanoparticles on the graphene surface.

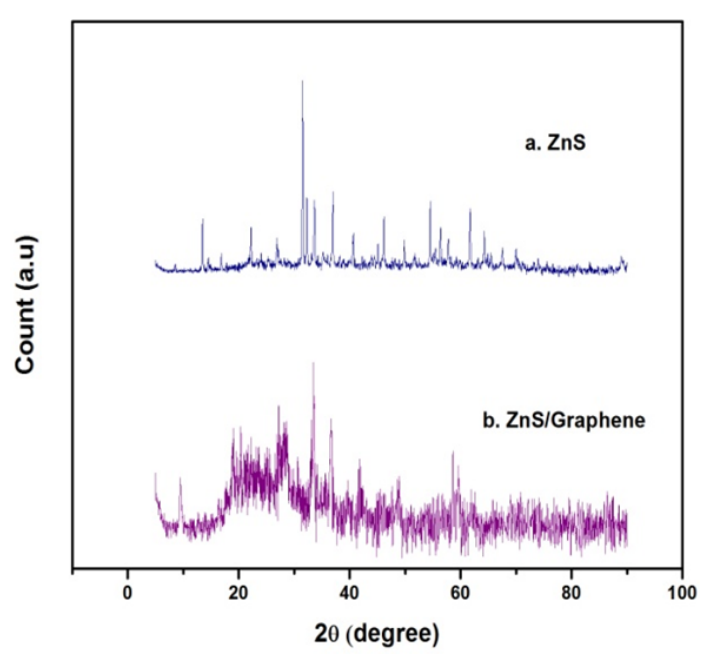

FIG. 1. XRD of $\mathrm{ZnS}$ and $\mathrm{ZnS} / \mathrm{Graphene}$

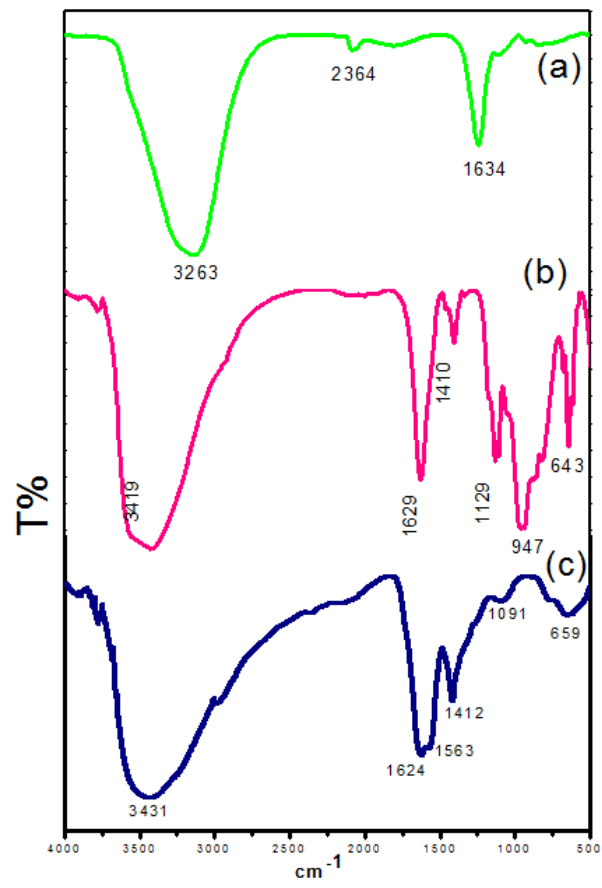

FIG. 2. FTIR spectra of (a) $\mathrm{ZnS} / \mathrm{G}$ (b) $\mathrm{ZnS}$ and (c) G

\subsection{SEM and TEM analysis of the samples}

The surface morphology of the samples was studied by electron microscopy. SEM and TEM images of G and $\mathrm{ZnS} / \mathrm{G}$ composites at different resolutions reveal the $2 \mathrm{D}$ structure of $\mathrm{G}$ sheets and the uniform distribution of $\mathrm{ZnS}$ nanoparticles on the surface of $\mathrm{G}$ with low and high magnification, as shown in Figs. 3 \& 4 . Energy dispersive $\mathrm{X}$-ray analysis (EDX) results demonstrate the presence of $\mathrm{ZnS}$ in the corresponding samples [10].

Figure 5(a) illustrates that EDX of graphene shows the weight percentage of carbon $93.64 \%$ and oxygen $06.36 \%$ and Fig. 5(b) shows the edax of $\mathrm{ZnS}$ decorated graphene nanocomposites shows the weight percentage of carbon $71 \%$, oxygen $3 \%$, Zinc $22 \%$ and Sulphur $4 \%$ present in the corresponding samples.

The EDX results explains the composition of elements such as $\mathrm{C}, \mathrm{O}, \mathrm{S}$ and $\mathrm{Zn}$ for the corresponding samples and discussed above.

\subsection{Electrochemical activity towards $\mathrm{H}_{2} \mathrm{O}_{2}$}

The collective electro-catalytic effect of nanoparticles and graphene towards $\mathrm{H}_{2} \mathrm{O}_{2}$ is well-documented in the literature. In the present study, the enzymatic generation of hydrogen peroxide is achieved in the reaction layer of the $\mathrm{G}$ or $(\mathrm{G} / \mathrm{ZnS})$ film. In order to investigate the electro-catalytic performance towards the electrochemical reaction of hydrogen peroxide at the $\mathrm{G}$ or $(\mathrm{G} / \mathrm{ZnS})$ film, cyclic voltammetry $(\mathrm{CV})$ has been performed. The CVs with $\mathrm{ZnS}$ and $\mathrm{G} / \mathrm{ZnS}$ film modified CPE before and after addition of $10 \mu \mathrm{M} \mathrm{H}_{2} \mathrm{O}_{2}$ in $0.1 \mathrm{M}$ phosphate buffer solution $(\mathrm{pH} \mathrm{7)}$ are shown in Figs. 6 and 7. The two electrodes show only a small background current in the 


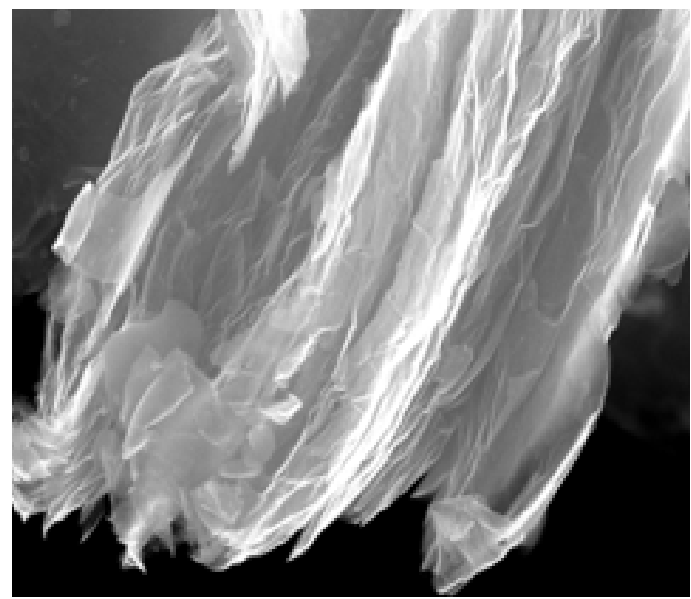

(A)

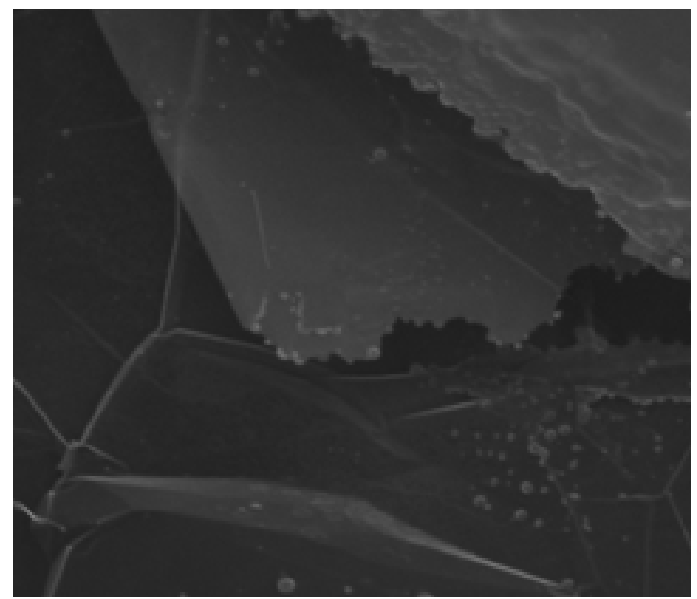

(B)

FIG. 3. SEM images of (A) $\mathrm{G}$ and (B) $\mathrm{ZnS} / \mathrm{G}$
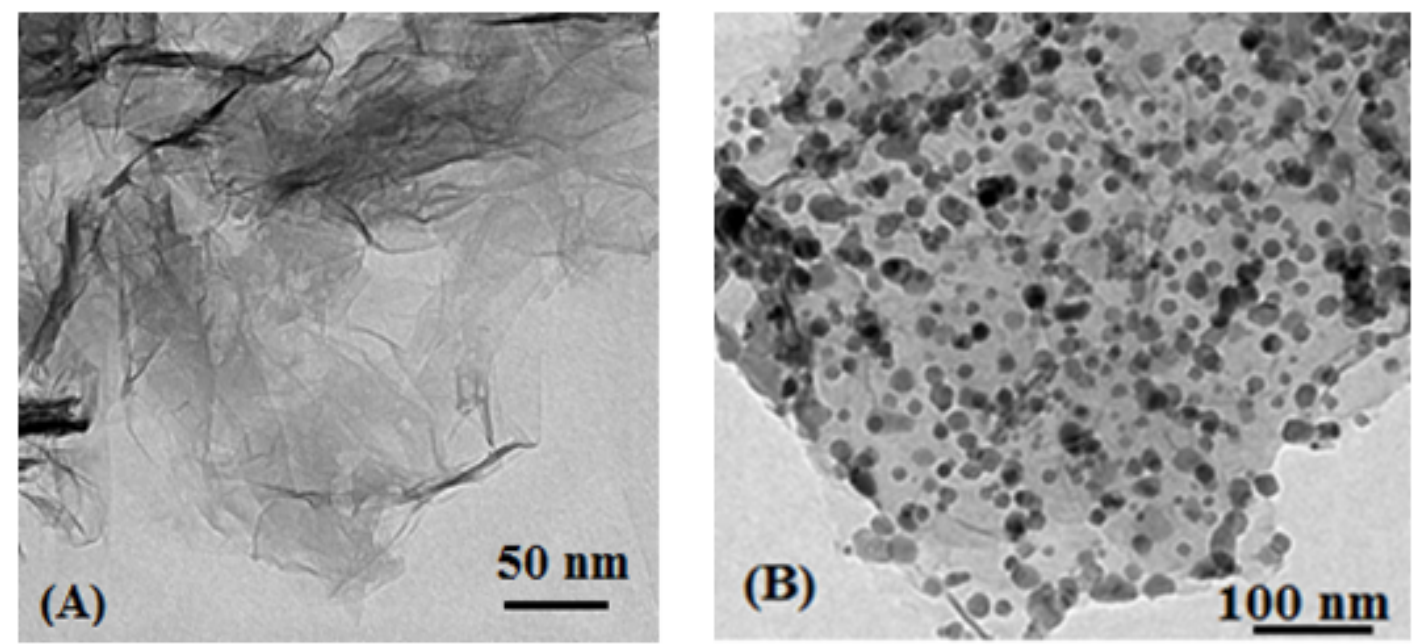

FIG. 4. TEM Images of (A) $\mathrm{G}$ and (B) $\mathrm{ZnS} / \mathrm{G}$
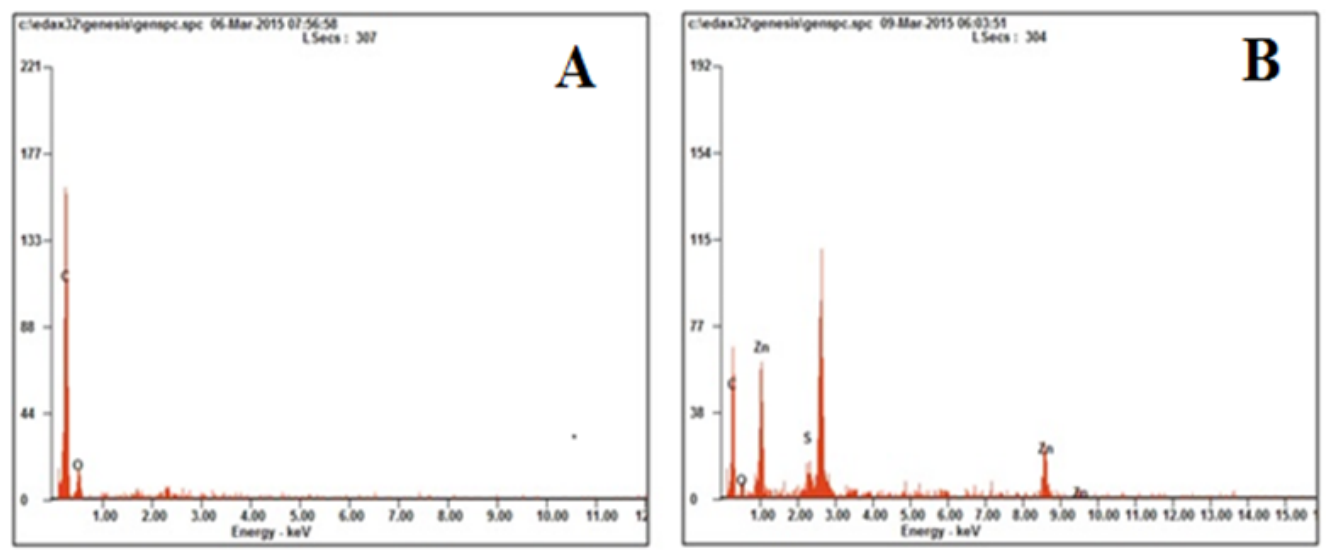

FIG. 5. EDX spectra of (A) G and (B) $\mathrm{ZnS} / \mathrm{G}$ 
absence of hydrogen peroxide. Upon addition of hydrogen peroxide, the $\mathrm{CV}$ of $\mathrm{G} / \mathrm{ZnS}$ modified electrode changed with obvious increase of the current relative to that of G. A pair of well-defined redox peaks appears with G/ZnS electrode. This is due to the high electron transfer rate of the G/ZnS/GOD/NA/CP electrode, high aspect ratio and huge working surface area of the nanocomposite.

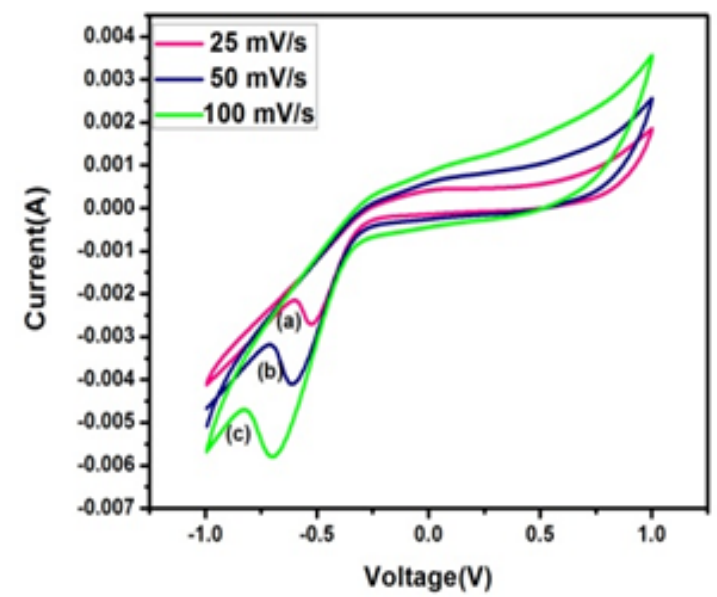

FIG. 6. $\mathrm{CV}$ of $\mathrm{G} / \mathrm{GOD} / \mathrm{NA} / \mathrm{CPE}$ in $0.1 \mathrm{M}$ PB solution ( $\mathrm{pH}$ 7) containing $0.3 \mathrm{mM} \mathrm{H}_{2} \mathrm{O}_{2}$ at a scan rate of
(a) $25 \mathrm{mV} / \mathrm{s}$;
(b) $50 \mathrm{mV} / \mathrm{s}$;
(c) $100 \mathrm{mV} / \mathrm{s}$

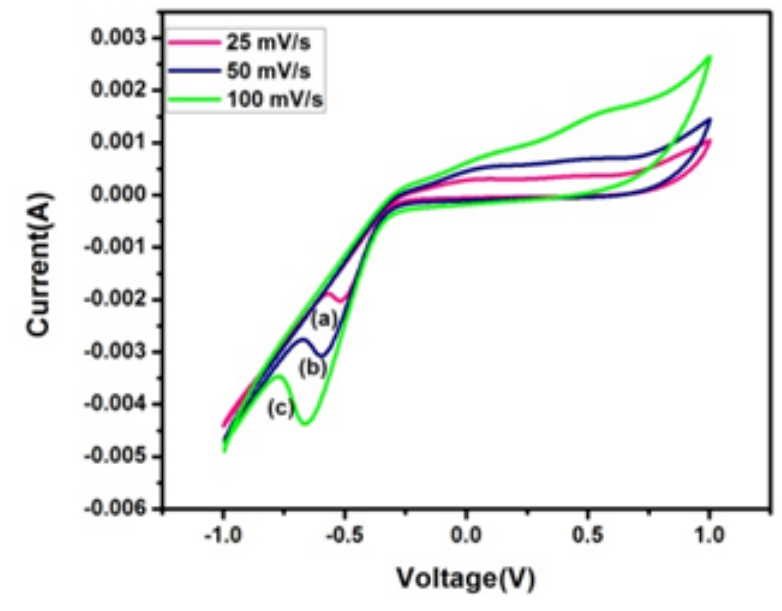

Fig. 7. CV of $\mathrm{ZnS} / \mathrm{G} / \mathrm{GOD} / \mathrm{NA} / \mathrm{CPE}$ in 0.1 MPB solution ( $\mathrm{pH} 7)$ containing $0.3 \mathrm{mM} \mathrm{H}_{2} \mathrm{O}_{2}$ at a scan rate of
(a) $25 \mathrm{mV} / \mathrm{s}$;
(b) $50 \mathrm{mV} / \mathrm{s}$;
(c) $100 \mathrm{mV} / \mathrm{s}$

\subsection{Electrochemical activity towards glucose}

Figures 8 \& 9 illustrates the $\mathrm{CV}$ responses of G/GOD/NA/CPE and G/ZnS/GOD/NA/CPE with the addition of $100 \mu \mathrm{M}$ glucose recorded at a scan rate of 25,50 and $100 \mathrm{mV} / \mathrm{s}$. G/ZnS/GOD/NA/CPE exhibits a couple of redox peaks versus $\mathrm{Ag} / \mathrm{AgCl}$ reference electrode, showing the potential characteristic of graphene. An increase in current has also been observed from the $\mathrm{CV}$ curve of $\mathrm{ZnS} / \mathrm{G} / \mathrm{GOD} / \mathrm{NA} / \mathrm{CPE}$ with glucose in PBS compared to $\mathrm{ZnS} / \mathrm{ChOx} / \mathrm{NA} / \mathrm{GCE}$ with glucose in PBS. The origins of well-defined redox peaks from the $\mathrm{CV}$ curve of $\mathrm{G} / \mathrm{ZnS} / \mathrm{GOD} / \mathrm{NA} / \mathrm{CP}$ electrode in PBS with $100 \mu \mathrm{M}$ glucose is due to the $\mathrm{H}_{2} \mathrm{O}_{2}$ generation during the oxidation of glucose by GOD. In addition to this, because of high surface area of G/ZnS, GOD attached to the surfaces of G/ZnS facilitates the fast and direct electron transfer between the active sites of immobilized GOD and electrode surface which leads to well-defined peaks. Therefore, glucose is efficiently detected with the G/ZnS/GOD/ NA/CPE.

\section{Conclusions}

Graphene nanosheets have been successfully substituted with ZnS nanoparticles and GOD has been immobilized on the G-ZnS/CP electrode. The incorporation of Graphene into the electrode increases the surface area and serves as an excellent support for $\mathrm{ZnS}$ nanoparticles that effectively catalyze redox reactions involving $\mathrm{H}_{2} \mathrm{O}_{2}$. In addition, the combination of $\mathrm{G}$ and $\mathrm{ZnS}$ nanoparticles facilitates the low potential amperometric detection of glucose and exhibits both good reproducibility and long-term stability of the biosensor, thereby providing a suitable platform for biosensor design and other biological applications.

\section{Acknowledgements}

We are grateful to The Director, CLRI, Chennai, for his kind permission to publish this work. 


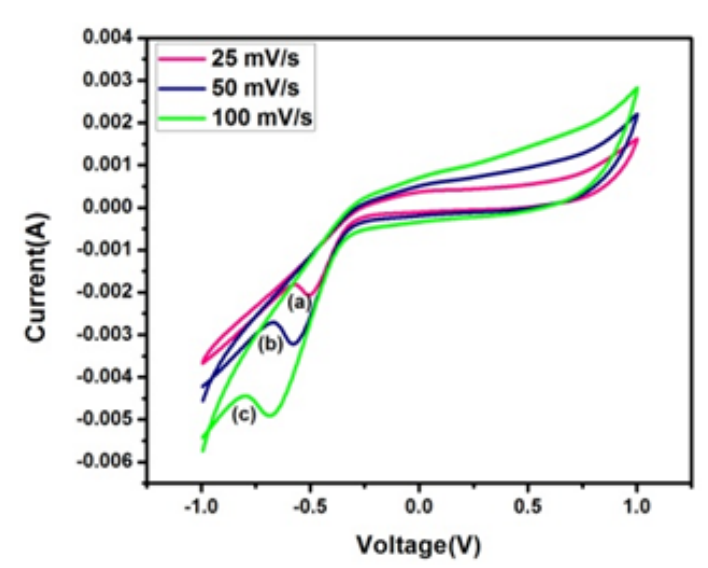

FIG. 8. $\mathrm{CV}$ of $\mathrm{G} / \mathrm{GOD} / \mathrm{NA} / \mathrm{CPE}$ in 0.1 M PB solution ( $\mathrm{pH} 7$ ) containing $100 \mu \mathrm{M}$ cholesterol at a scan rate of 25,50 and $100 \mathrm{mV} / \mathrm{s}$

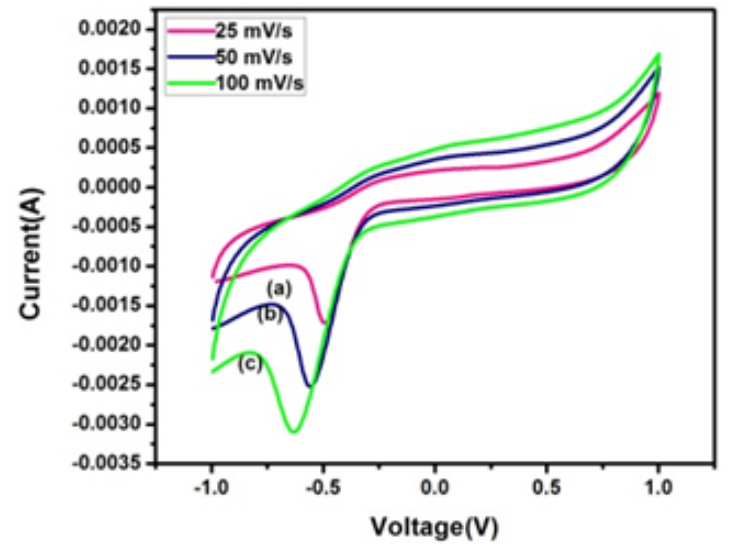

FIG. 9. $\mathrm{CV}$ of $\mathrm{ZnS} / \mathrm{G} / \mathrm{GOD} / \mathrm{NA} / \mathrm{CPE}$ in $0.1 \mathrm{M}$ PB solution ( $\mathrm{pH} 7$ ) containing $100 \mu \mathrm{M}$ cholesterol at a scan rate of 25,50 and $100 \mathrm{mV} / \mathrm{s}$

\section{References}

[1] Wild S., Roglic G., et al. Global prevalence of diabetes estimates for the year 2000 and projections for 2030. Diabetes Care, 2004, 27 (5), P. 1047-1053.

[2] American Diabetes Association. Diagnosis and classification of diabetes mellitus. Diabetes Care, 2003, 36 (Suppl 1), S67-S74.

[3] Bakker E., Qin Y. Electrochemical sensors. Anal. Chem., 2006, 78 (12), P. 3965-3984.

[4] Luo X., Morrin A., Killard A.J., Smyth M.R. Application of nanoparticles in electrochemical sensors and biosensors. Electroanalysis, 2006, 18 (4), P. 319-326.

[5] Heller A., Feldman B. Electrochemical glucose sensors and their applications in diabetes management. Chem. Rev, 2008,108 (7), P. 2482-2505.

[6] Dungchai W., Chailapakul O., Henry C.S. A low-cost, simple, and rapid fabrication method for paper-based microfluidics using wax screen-printing. Analyst, 2011, 136 (1), P. 77-82.

[7] Nie Z.H., Nijhuis C.A., et al. Electrochemical sensing in paper-based microfluidic devices. LabChip, 2010, 10 (4), P. 477-483.

[8] Wang F., Hu S. Electrochemical sensors based on metal and semiconductor nanoparticles. Microchim Acta, 2009, 165 (2), P. 1-22.

[9] Wang J. Nanomaterial-based electrochemical biosensors. Analyst, 2005, 130 (4), P. 421-426.

[10] Rita J., Sasi S. Florence optical, structural and morphological studies of bean-like Zns nanostructures by aqueous chemical method. Chalcogenide Letters, 2010, 7 (4), P. 269-273.

[11] Xu J.F., Ji W., et al. Preparation of ZnS nanoparticles by ultrasonic radiation method. Appl. Phys. A, 1998, 66, P. 639-641.

[12] Konstantin K.N., Ozbas B., et al. Raman Spectra of Graphite Oxide and Functionalized Graphene Sheets. Nano Lett., 2008,8 (1), P. $36-41$.

[13] Schniepp H.C, Li J.L., et al. Functionalized single graphene sheets derived from splitting graphite oxide. J. Phys. Chem. B, 2006,110 (17), P. 8535-8539.

[14] Yang W., Ratinac K.R., et al. Carbon nanomaterials in biosensors: should you use nanotubes or graphene? Angew. Chem., Int. Ed., 2010, 49 (12), P. 2114-2138.

[15] Zhu Z., Garcia G.L., et al. A Critical Review of Glucose Biosensors Based on Carbon Nanomaterials: Carbon nantubes and graphene. Sensors, 2012, 12 (5), P. 5996-6022.

[16] Kuwahara T., Ohta H., Kondo M., Shimomura M. Immobilization of glucose oxidase on carbon paper electrodes modified with conducting polymer and its application to a glucose fuell cell. Bioelectrochemistry, 2008, 74 (1), P. 66-72. 